The Israeli Journal of Aquaculture - Bamidgeh, IJA_73.2021.1231861, 9 pages

CCBY-NC-ND-4.0 • https://doi.org/10.46989/001c.21212

The $I J A$ is a peer-reviewed open-access, electronic journal, freely available without charge to users

Produced by the AquacultureHub non-profit Foundation

Sale of $I J A$ papers is strictly forbidden

\title{
Effects of concentrated dephenolic cottonseed protein instead of fish meal on stress resistance of Penaeus monodon
}

\author{
Xian-Bin Mo ${ }^{a, c \#}$, Cong-Ling Huang ${ }^{b \#}$, Song Jiang ${ }^{a, c}$, Fa-Lin Zhou ${ }^{c *}$, Yun-Dong \\ Lic,d, Qi-Bin Yang $^{c, d}$, Jian-Hua Huang ${ }^{c, d}$, Li-Shi Yang ${ }^{c, d}$, Shi-Gui Jiang ${ }^{c}$ \\ ${ }^{a}$ College of Fisheries and Life Sciences, Shanghai Ocean University, Shanghai 201306, P.R. \\ China \\ ${ }^{b}$ Zhuhai modern agricultural development center, 519070, Zhuhai, Guangdong Province, P.R. \\ China \\ ${ }^{c}$ Key Laboratory of South China Sea Fishery Resources Exploitation and Utilization, Ministry of \\ Agriculture and Rural Affairs; South China Sea Fisheries Research Institute, Chinese Academy of \\ Fishery Sciences, 510300, Guangzhou, Guangdong Province, P.R. China \\ ${ }^{d}$ Shenzhen Base of South China Sea Fisheries Research Institute, Chinese Academy of Fishery \\ Sciences, Shenzhen 518108, P.R. China
}

Keywords: Penaeus monodon, Concentrated dephenol cottonseed protein, Salinity stress, Non-specific immunity

\begin{abstract}
To explore the effect of concentrated dephenolic cottonseed protein (CDCP) partly instead of fish meal on the non-specific immune of Penaeus monodon, we designed a single factor test to study the four types of non-specific immunity of $P$. monodon hepatopancreas after acute salinity stress. A total number of 5,400 P. monodon were selected with an initial body weight of $1.76 \pm 0.15 \mathrm{~g}$ and randomly divide into 6 groups ( 3 replicates per group, 900 tails per replicate). Shrimp were feed with two protein level diets (Diet A and Diet B). After 8 weeks of feeding, $P$. monodon were randomly selected with an average weight of $14.71 \pm 1.06 \mathrm{~g}$ in each feed group, and subjected to acute salinity stress of $10 \mathrm{ppt}$ and $20 \mathrm{ppt}$ after temporary rearing, and the heat shock protein 70 (HSP70), $\mathrm{Na}^{+}-\mathrm{K}^{+}$-ATPase, cortisol and the content of alkaline phosphatase (ALP) were measured. The results of the study showed that when the CDCP partially replaced fish meal of $P$. monodon diet, the hepatopancreas HSP7O, and the contents of $\mathrm{Na}^{+}-\mathrm{K}^{+}$-ATPase and cortisol were significantly higher than those of the control group. In the acute salinity change, there was no significant difference in the survival rate of $P$. monodon at $48 \mathrm{~h}$ under the two salinity stresses, and the four immune indexes showed different trends. The expression level of Cortisol was more prominent than that of HSP70, which could better reflect the stress degree of $P$. monodon. Most of the indicators showed a trend of rising and then falling and then rising compared with the original level, and the changes of the four indicators of hepatopancreas in the Diet $B$ group were significantly higher than those in the Diet A group at most time point of the two salinities.
\end{abstract}

* Corresponding author: Dr. Fa-Lin Zhou. 231 Xingang Road West, Haizhu District, Guangzhou City, Guangdong Province, 510300, PR China. E-mail address: zhoufalin@aliyun.com; Phone: +86 02084451346 \# These authors contributed equally to this work 


\section{Introduction}

In shrimp culture, feed cost accounts for more than half of the total cost (Jiang et al.,2018). At present, shrimp feed mainly relies on fish meal as protein source and the resource of fish meal is limited and the demand is increasing rapidly (Zhang et al.,2018). Some scholars carried out the research on the replaceable of plant protein to reduce the demand of fish meal in shrimp feed and found out the most suitable amount of plant protein in diet (Yu et al.,2016; Riche et al., 2011; Liu et al.,2012). However, some studies showed that when the animal protein content in feed was too low, it would have a certain impact on the growth and immune performance of cultured organisms (Niu et al.,2015; Gomez-Requeni et al.,2004). Therefore, the immune and anti-stress properties of cultured organisms fed with plant protein instead of fish meal protein need to be further studied.

Cortisol, HSP70 and ALP are important indicators involved in the body's stress immune response, and their levels and activities are closely related to the health and immunity of aquatic animals (Flik G et al.,2006; Yvette $\mathrm{S}$ et al.,2011). $\mathrm{Na}^{+}-\mathrm{K}^{+}$-ATPase is a typical marker of osmoregulation (Xiao.,2018). Therefore, it is of great significance to study the change trend of the above four immune indexes for understanding the immune performance of cultured organisms. In this study, $P$. monodon was fed with normal fish meal protein level feed and CDCP partially replace fish meal feed for 8 weeks, and the changes of immune indexes were studied by acute salinity stress experiment. The experiment provides data reference for immune research of $P$. monodon fed with low fish meal protein, and provides theoretical reference for evaluation of environmental factors and health status of $P$. monodon.

\section{Feed formula and preparation.}

\section{Materials and Methods}

Fish meal, soybean meal, CDCP and peanut meal were used as the main protein sources, and the formula was designed according to the principle of equal energy and unequal protein. Two kinds of feeds (Table 1) were prepared: Diet A group (fish meal content in feed is $30 \%$ ) and Diet B group (fish meal content in feed is $10 \%$; CDCP content is $20 \%$ ). All feed materials were crushed through 80-mesh sieve, mixed step by step, and then stirred with water to make $1.00-$ and $1.50-$ $\mathrm{mm}$ diameter pellet feed, baked in $90{ }^{\circ} \mathrm{C}$ oven (put some water in the oven) for 2 hours, dried in the air-conditioned room, stored in $-20{ }^{\circ} \mathrm{C}$ refrigerator for standby.

\section{Experimental shrimp and feeding management.}

The experiment was carried out in the genetic and breeding center of $P$. monodon in the Ministry of Agriculture of the People's Republic of China. The $P$. monodon used in the experiment were selected as the core breeding family of the research group after several generations of continuous breeding. A total number of 5400 shrimp with the average body weight of $1.76 \pm 0.15 \mathrm{~g}$ were selected and divided into 2 feed groups and each feed group was set up with 3 parallel groups. Shrimp were feed 3 times a day at 8:00,17:00 and 22:00. The daily feeding amount was $7 \%-8 \%$ of the shrimp weight. The aquaculture water was sand filtered seawater. The water was changed $1 / 3$ every week, and the breeding period was 56 days. During the experiment, the micro tube aerator was used for 24 hours to aerate and increase oxygen. The water temperature was 27-32 ${ }^{\circ} \mathrm{C}$, the salinity was $31-33$, the $\mathrm{pH}$ was $7.8-8.2$, and the dissolved oxygen was $6.6-7.0 \mathrm{mg}$ / L.

\section{Experimental design and sample processing}

After the breeding experiment, $P$. monodon with an average weight of $14.71 \pm 1.06 \mathrm{~g}$ were selected from Diet $A$ and Diet $B$ respectively and temporarily reared for three days. The experiment was set up two salinity treatment groups of $10 \mathrm{ppt}$ and $20 \mathrm{ppt}$, and each treatment group had three parallel treatment groups. A number of 60 selected shrimp were placed in each black breeding bucket and no feed was given after the experiment started. At the time points of $0 \mathrm{~h}, 8 \mathrm{~h}, 16 \mathrm{~h}, 24 \mathrm{~h}, 32 \mathrm{~h}, 40 \mathrm{~h}$, and $48 \mathrm{~h}$, the hepatopancreas samples of 5 shrimp were cut, mixed, and put into a $1.5 \mathrm{~mL}$ cryopreservation tube. After sampling, immediately transfer to $-80^{\circ} \mathrm{C}$ refrigerator for storage for testing.

An appropriate amount of hepatopancreas tissue sample was taken, and the upper tissue fluid was absorbed with filter paper, weigh it and place it in a centrifuge tube, add the homogenate to $\mathrm{m}$ (tissue, $\mathrm{g}$ ): $\vee$ (homogenate, $\mathrm{ml})=1: 9$, and homogenize Select PBS ( $\mathrm{PH}=7.2-7.4$, concentration 
of $0.01 \mathrm{~mol} / \mathrm{L}$ ). Tissue homogenate was carried out by vortex shaker (G56E, Qite Analytical Instrument Company) and then centrifuged at 3000r.min ${ }^{-1} 4^{\circ} \mathrm{C}$ for 10 minutes, and the supernatant was taken for subsequent operation. The activities of four immune indexes, $\mathrm{Na}^{+}-\mathrm{K}^{+}-$ ATPase, HSP70, cortisol and ALP, were carried out according to the corresponding shrimp ELISA kit produced by Beijing Huabodeyi Biotechnology Co., Ltd., and the kit was determined by double antibody sandwich method.

\section{Data processing}

The experimental data were analyzed by One-Way ANOVA with SPSS25.0, and $P<0.05$ showed significant difference.

Table 1 Composition and nutrient content of experimental diets

\begin{tabular}{|c|c|c|}
\hline Ingredients (\%) & Diet A & Diet B \\
\hline Fish meal & 30 & 10 \\
\hline Soybean meal & 18 & 18 \\
\hline $\begin{array}{l}\text { Concentrated dephenolization } \\
\text { cottonseed protein }\end{array}$ & 0 & 20 \\
\hline Peanut meal & 10 & 10 \\
\hline Wheat flour & 21.99 & 17.1 \\
\hline Beer yeast & 3 & 3 \\
\hline Shrimp head meals & 5 & 5 \\
\hline Soybean protein concentrate & 4.8 & 6.2 \\
\hline Soybean lecithin & 1 & 1 \\
\hline Fish oil & 1 & 1 \\
\hline Soybean oil & 0.5 & 2.1 \\
\hline CAscorbic Phosphate ester & 0.1 & 0.1 \\
\hline Cholesterol & 0.5 & 0.5 \\
\hline Vitamin premixa & 1 & 1 \\
\hline Mineral premix ${ }^{b}$ & 1 & 1 \\
\hline $\mathrm{Ca}\left(\mathrm{H}_{2} \mathrm{PO}_{4}\right)_{2}$ & 1 & 1 \\
\hline Lysine & 0 & 0.97 \\
\hline Methionine & 0.1 & 0.47 \\
\hline Threonine & 0 & 0.55 \\
\hline Carboxymethylcellulose & 1 & 1 \\
\hline $\mathrm{Y}_{2} \mathrm{O}_{3}$ & 0.01 & 0.01 \\
\hline Sum & 100 & 100 \\
\hline \multicolumn{3}{|l|}{ Proximate composition } \\
\hline Moisture (\%) & 8.32 & 7.88 \\
\hline Crude protein $(\%)$ & 39.65 & 39.29 \\
\hline Crude lipid (\%) & 5.70 & 6.09 \\
\hline Ash (\%) & 11.89 & 10.47 \\
\hline
\end{tabular}

Note: 1. Vitamin premix $\left(\mathrm{g} \cdot \mathrm{kg}^{-1}\right): \mathrm{V}_{\mathrm{A}} 2.5 ; \mathrm{V}_{\mathrm{D}} 6.25 ; \mathrm{V}_{\mathrm{E}} 75 ; \mathrm{V}_{\mathrm{K}} 2.5 ; \mathrm{V}_{\mathrm{B} 1} 0.25 ; \mathrm{V}_{\mathrm{B} 2} 1.0 ; \mathrm{V}_{\mathrm{B} 3}$ $5.0 ; V_{B} 6.75 ; V_{B 12} 2.5$; folic acid 0.25 ; biotin 2.5 ; inositol 379 ; cellulose $500 ; 2$. Premix Minerals $\left(\mathrm{g} \cdot \mathrm{kg}^{-1}\right), \mathrm{KCl}, 90 ; \mathrm{KI} 0.04, \mathrm{NaCl}, 40 \mathrm{~g} ; \mathrm{CuSO}_{4} \cdot 5 \mathrm{H}_{2} \mathrm{O} ; 3 . \mathrm{ZnSO}_{4} \cdot 7 \mathrm{H}_{2} \mathrm{O} ; 4$. $\mathrm{CoSO}_{4} \cdot 7 \mathrm{H}_{2} \mathrm{O}, 0.02 ; \mathrm{FeSO}_{4} \cdot 7 \mathrm{H}_{2} \mathrm{O}, 20 ; \mathrm{MnSO}_{4} \cdot \mathrm{H}_{2} \mathrm{O}, 3 ; \mathrm{MgSO}_{4} \cdot 7 \mathrm{H}_{2} \mathrm{O}, 124 ; \mathrm{Ca}\left(\mathrm{H}_{2} \mathrm{PO}_{4}\right)_{2} \cdot 2 \mathrm{H}_{2} \mathrm{O}$, $500 ; \mathrm{CaCO}_{3}, 215$.

\section{Results}

Effect of CDCP instead of partial fish meal on immune indexes of Penaeus monodon.

The effects of CDCP instead of fish meal on activities of ALP, cortisol, HSP70 and $\mathrm{Na}^{+}-\mathrm{K}^{+}-$ ATPase of $P$. monodon were shown in Figure 1(A), Figure 2(A), Figure $\mathbf{3}(\mathbf{A})$ and Figure $\mathbf{4 ( A )}$ for 0 h. The result in Figure $\mathbf{1}(\mathbf{A})$ showed that the ALP activity of $P$. monodon in Diet $B$ group was significantly different from that in Diet A group after 56 days of culture experiment $(P<0.05)$. The 
activities of cortisol, HSP70, $\mathrm{Na}^{+}-\mathrm{K}^{+}$-ATPase in $P$. monodon in Diet $\mathrm{B}$ group were significantly different from those in Diet A group $(P<0.01)$.

Effects of salinity of 10ppt on nonspecific immune indexes of Penaeus monodon.

Compared with the experimental group Diet B, after $8 \mathrm{~h}$ of stress, the ALP activity of Diet A group reached the highest, which was significantly higher than that of Diet B group $(P<0.01)$, and then decreased at $16 \mathrm{~h}$. At $48 \mathrm{~h}$, the ALP activity of Diet B group was higher than that of Diet A group $(P<0.05)$. And Diet $B$ group rose to the highest at $48 \mathrm{~h}$, while Diet $A$ group rose to the highest at $8 \mathrm{~h}$ (Figure 1-A). In (Figure 2-A), the HSP70 of the Diet A group reached the highest at $8 \mathrm{~h}$, which was significantly higher than that of the Diet $\mathrm{B}$ group $(P<0.01)$. The Diet $\mathrm{B}$ group rose to the highest at $24 \mathrm{~h}$, and then, became the same level with Diet $A$ group, which presented a trend of decreasing at first and then increasing. In (Figure 3-A), the expression of cortisol in Diet $B$ group reached the highest at $0 \mathrm{~h}$, and then showed a trend of decreasing and then increasing. At most time points, cortisol in Diet B group was significantly higher than that in Diet A group $(P<0.01)$. In (Figure 4-A), the activity of Na-K-ATPas in hepatopancreas of $P$. monodon showed a trend of increasing at first and then decreasing, while Na-K-ATPas reached the highest level in Diet A group at $16 \mathrm{~h}$ and Diet B group at $32 \mathrm{~h}$.

\section{Effects of salinity 20ppt stress on nonspecific immune indexes of Penaeus monodon.}

The ALP in hepatopancreas of control group Diet A and experimental group Diet B showed a turning point from increasing to decreasing after 16 hours of stress. during 8-48 hours, the ALP expression in hepatopancreas of Diet $B$ group was higher than that of Diet A group at most time points, and there were significant differences $(P<0.01)$ (fig. 1-B). The expression of HSP70 in Diet $A$ of control group and Diet B of experimental group showed an inflection point from increasing to decreasing at $16 \mathrm{~h}$, and reached the highest at $32 \mathrm{~h}$ in Diet A group and $8 \mathrm{~h}$ in Diet B group (fig. 2-B). The expression of Cortisol in hepatopancreas of Diet A group and Diet B group increased at $8 \mathrm{~h}$, showed an inflection point from increasing to decreasing at $16 \mathrm{~h}$, and showed a trend of returning to $0 \mathrm{~h}$ expression level at $48 \mathrm{~h}$, and there was a significant difference between Diet $B$ group and Diet A group $(P<0.01)$ (Figure 3-B). In (Figure 4-B), the expression of $\mathrm{Na}^{+}-\mathrm{K}^{+}-$ ATPase in Diet A group and Diet B group showed an increasing trend from 0 to $0-16 \mathrm{~h}$ hours, and then both groups showed a decreasing and then increasing trend, and their expression levels at $48 \mathrm{~h}$ were higher than those at $0 \mathrm{~h}$.

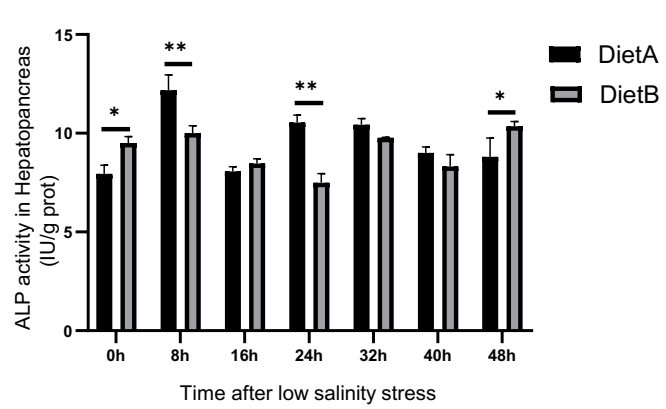

(A)

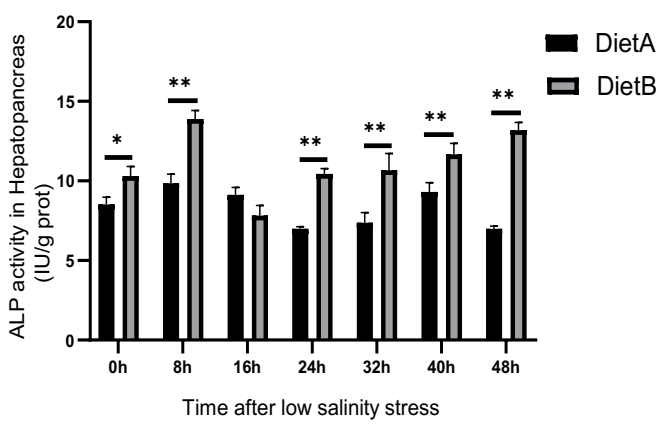

(B)

Figure 1 The effect of salinity stress on ALP activity of Penaeus monodon

$*$ means that the difference between groups is significant at the same time point $(p<0.05)$

$i^{* *}$ means that the difference between groups is extremely significant at the same time point $(p<0.01$. (A) is the stress Figure of salinity $10 \mathrm{ppt}$, and (B) is the stress Figure of salinity 20ppt. Same as below. 


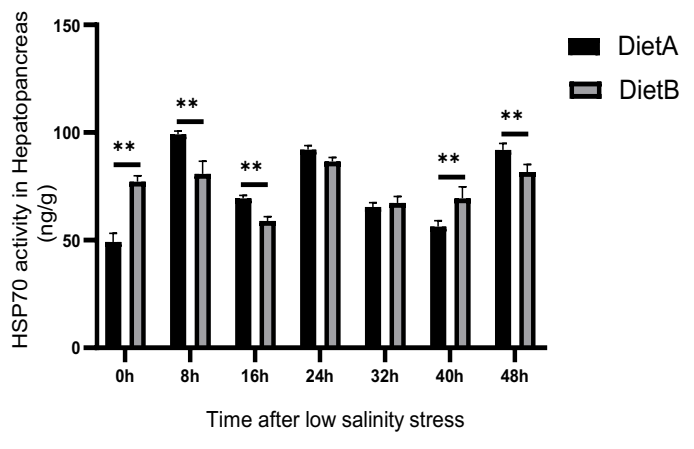

(A)

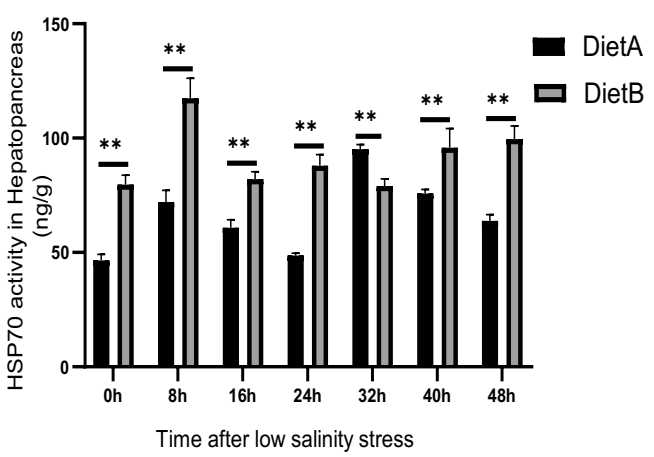

(B)

Figure 2 Effects of salinity stress on HSP70 of Penaeus monodon

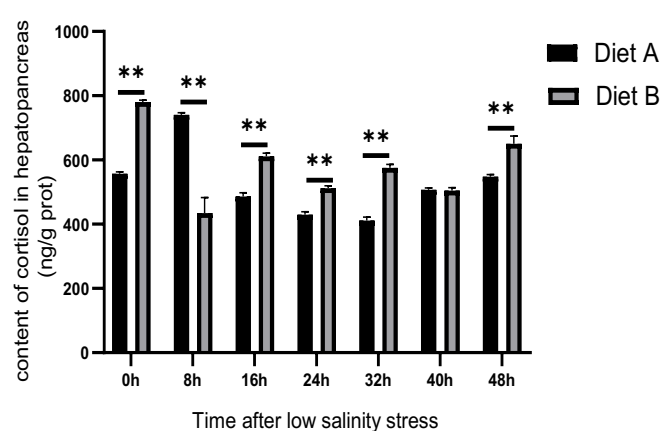

(A)

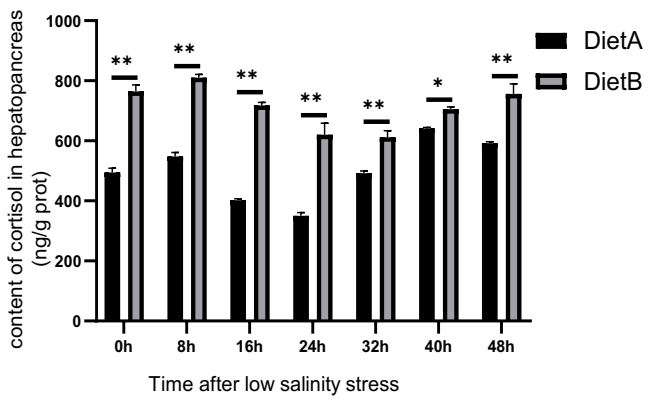

(B)

Figure 3 Effects of salinity stress on the cortisol content of Penaeus monodon

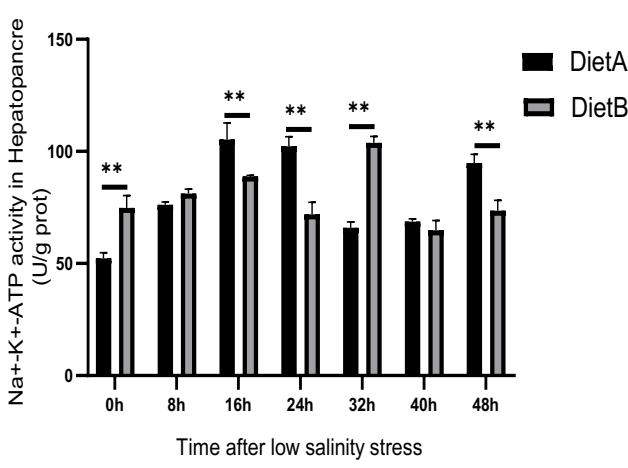

(A)

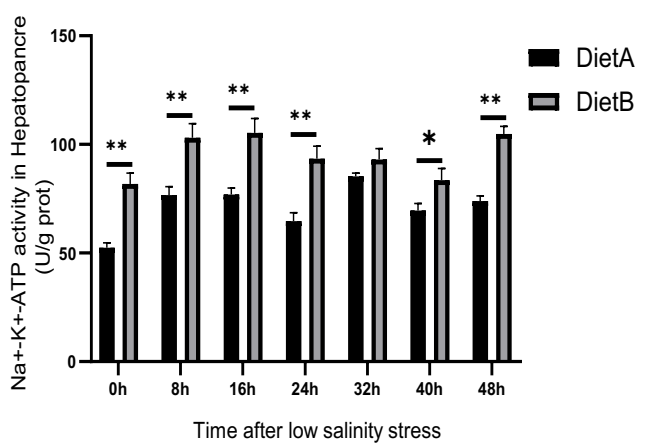

(B)

Figure 4 Effects of salinity stress on the activity of $\mathrm{Na}^{+}-\mathrm{K}^{+}$-ATPase in Penaeus monodon

\section{Discussion}

Effect of CDCP instead of fish meal on immune indexes of $P$. monodon.

Many studies showed that the plant protein added in feed wouldl have an impact on the immune index of fish (Sun et al.,2013; Xu et al.,2012; Lin et al.,2011). Lin (Lin et al.,2011) found that the increase of the level of CDCP replacing fish meal could affect the total antioxidant capacity of hepatopancreas, the activities of glutamic oxaloacetic transaminase (GOT), glutamic pyruvic transaminase (GPT), superoxide dismutase (SOD) and liver glycogen content of tilapia. In the low fish meal feed of tilapia, the level of CDCP replacing fish meal should not exceed $50 \%$. Excessive substitution level would have a negative impact on the immune response of tilapia. Lin (Lin et 
al.,2010) used different plant protein sources to replace fish meal in tilapia feed, it was found that rapeseed meal and cottonseed meal had the greatest influence on GOT, GPT and SOD activities in hepatopancreas of tilapia, followed by peanut meal, and soybean meal had the least influence. Zhang (Zang et al.,2018) replaced fish meal with high-protein cottonseed meal, it was found that with the increase of the proportion of high-protein cottonseed meal, the contents of phenoloxidase, total superoxide dismutase, acid phosphatase, alkaline phosphatase in the serum of Litopenaeus vannamei and malondialdehyde in the hepatopancreas changed. When the substitution ratio did not exceed $50 \%$, the immune system of $L$. vannamei was not negatively affected, while the substitution amount reached $40 \%$, the alkaline phosphatase activity decreased significantly. In this experiment, $66.67 \%$ of fish meal was replaced by CDCP. After 56 days of culture experiment, it was found that the four nonspecific immune indexes of cortisol, $\mathrm{Na}^{+}-\mathrm{K}^{+}-$ ATPase, HSP70 and ALP in hepatopancreas were significantly higher than those in the control group, which indicated that adding a certain amount of CDCP in P. monodon feed could stimulate the immunity of the organism itself.

Evaluation of stress degree of $P$. monodon under low salinity stress.

The adaptation of crustaceans to salinity was mainly through the adjustment of osmotic pressure of the body. When the salinity of water suddenly changed, the body needed to make dynamic osmotic adjustment through osmotic pressure adjusting organs to reach a new equilibrium state that can adapt to the external environment. If the salinity changed too much or exceeded the adjustment ability of the body, it would cause irreversible damage, and then caused corresponding changes in related physiological indexes such as feeding, respiratory metabolism, immune enzymes and hormones, and even affect the growth and survival of organisms (Guo et al.,2013). In this study, there was no significant difference in the mortality of $P$. monodon for 48 hours under the stress of different salinity groups. This indicates that $P$. monodon had strong salinity regulation and adaptability.

Some studies had shown that the hypothalamus-pituitary-adrenal axis (HPI) of fish was activated under the action of environmental pressure, which lead to the synthesis and release of stress hormones such as cortisol (Wendelaar et al.,1997). Cortisol played an important role in osmotic pressure regulation, which could stimulate proliferation and differentiation of gill chlorinesecreting cells, regulate water-salt balance, activate $\mathrm{Na}^{+}-\mathrm{K}^{+}$-ATPase activity, enhance salinity tolerance and maintain osmotic pressure balance (McCormick et al.,2001; Pelis et al.,2001; Zhou et al.,2003). The results of salinity of 10ppt stress in this experiment showed that cortisol in Diet A feed group increased to the highest level at $8 \mathrm{~h}$, then decreased to the lowest level at $32 \mathrm{~h}$, and then increased and tended to return to the original level. However, under salinity stress of 20ppt, it increased at $8 \mathrm{~h}$ and decreased to the lowest level at $24 \mathrm{~h}$, and the subsequent performance was consistent with the stress trend of salinity of $10 \mathrm{ppt}$. Therefore, it was speculated that the acute change of salinity had strong stress on $P$. monodon, which leaded to the higher expression of cortisol at $8 \mathrm{~h}$ than at $0 \mathrm{~h}$. The expression dropped to the lowest level at $32 \mathrm{~h}$ and $24 \mathrm{~h}$ respectively, which probably because the immune system was challenged during this period, and the material metabolism of its body cells was disordered, which was also an adaptive adjustment stage of the body to this salinity stress, and gradually adjusted and adapted in the following time, so the nonspecific immune stress index rose again and had a tendency to return to the level before the initial stress. Cortisol in Diet B group decreased significantly at $8 \mathrm{~h}$, and then increased at first and then decreased, and tended to return to the original level around $48 \mathrm{~h}$. Under the stress of salinity of 10ppt, cortisol in Diet B group showed a completely opposite trend to that in Diet A group at $8 \mathrm{~h}$. It was speculated that cortisol was a sensitive indicator of stress, and the stress degree was 0-8 hours, and $P$. monodon was already in disorder, so it decreased significantly. The expression of cortisol in Diet B group was significantly higher than that in Diet A group at most time points in two stress salinities $(P<0.01)$. The result may be that the expression of cortisol in Diet $\mathrm{B}$ group was significantly higher than that in Diet A group at the initial stage after 56 days of culture experiment. Therefore, the expression of cortisol in Diet B group was significantly higher than that in Diet A group after salinity stress.

Heat shock protein (HSP) was a family of polypeptide proteins existing in all organisms. It was a highly conserved family of protein molecules in the process of biological evolution. Among them, HSP70 family had the most members. It had been reported that HSP70 was not only extremely sensitive to external temperature, but also susceptible to dissolved oxygen, hunger, 
acidity, crowding and other stimuli (Vinagre et al.,2012). A large number of studies had shown that HSP70 could maintain intracellular homeostasis, and its large expression in cells could significantly improve the viability of cells and improve their tolerance to environmental stress or injury (Wu et al.,2006). However, the current research on HSP70 had rarely been reported in invertebrates, especially $P$. monodon. This study found that HSP70 increased significantly at 8h during both salinity stresses, followed by a process of decrease and then increase, and the expression of HSP70 in the Diet B group was significantly higher than that of the Diet A group at most time points. This may be because the immune system of $P$. monodon had been challenged, and the material metabolism of the cells of the body had been disordered, and then gradually adjusted, and gradually adapted to the subsequent time. However, Guo (Guo et al.,2013) found that, HSP70 cultured in three different salinity environments showed a slow increase trend, but the salinity had no significant effect on HSP70 of the juvenile pomfret at this stage, which was inconsistent with the results of this study. It was speculated that the same stress was caused by different species. The indicator expression would be different, and it may also be caused by the different time interval between the sampling time points.

\section{The effect of low salt stress on enzyme activity of $P$. monodon.}

Alkaline phosphatase (ALP) was an important non-specific phosphohydrolase in the process of animal energy metabolism and an important component of lysosomal enzymes. It played an important role in the absorption and utilization of nutrients in fish and its immune response. The activity of ALP was usually used as an evaluation index for shrimp non-specific immunity (Xiao et al., 2010; Du et al.,2013). From the results of this experiment, in the feed group with stress salinity of 10ppt and 20ppt, $P$. monodon's non-specific immunity indexes showed an increasing trend in the initial stage of stress, but as time went on, hepatopancreas ALP showed a significant decrease and significant upward trend. This indicates that with the development of time, this stress caused the damage of the immune system of $P$. monodon, the enzyme activity in the body appeared intermittently low activity, and then the body adjusted and recovered through its own, and the enzyme activity increased again. This is an adaptation process of $P$. monodon to drastic external environmental changes. Research of Qiao on Procambarus clarkia found that with the increase of the stress concentration, the ALP and acid phosphatase (ACP) of $P$. clarkii also increased significantly, and showed a decreasing trend as time passed (Qiao et al.,2020). The result suggested that with the increase of salinity, the body consumed a lot of ATP in order to carry out osmotic adjustment to maintain the body's steady state, and the inorganic phosphoric acid necessary for the synthesis of ATP requires ACP and ALP to jointly catalyze the production of phospholipids, which leaded to ALP and ACP increased activity, thereby enhancing the body's immune activity. Afterwards, it decreased significantly, and the activities of ALP and ACP in the body were significantly inhibited, indicating that with time, salinity stress will affect the body's immune system, thereby reducing the body's disease resistance.

$\mathrm{Na}^{+}-\mathrm{K}^{+}$-ATPase was the most important protease for osmotic adjustment of crustaceans, mainly located on the basal plasma membrane, and it participated in the active transport of $\mathrm{Na}^{+}$ and $\mathrm{K}^{+}$ions across the membrane on both sides of the cell, thereby maintaining the ion gradient and membrane potential inside and outside the cell, regulating the volume of the cell, and driving the transport of sugar and amino acids in the cell (Fang et al.,2001). The change of $\mathrm{Na}^{+}-\mathrm{K}^{+}-$ ATPase was an important detection index for the immune regulation of aquatic animals with euryhalinity. Steven studied Gammarus pulex and found that the $\mathrm{Na}^{+}-\mathrm{K}^{+}$-ATPase activity of the gills of aquatic crustaceans in high-salinity water environments increased after entering lowsalinity water environments (Steven et al.,2006). In the studies of $L$. vannamei and Marsupenaeus japonicus respectively, it was found that the gill $\mathrm{Na}^{+}-\mathrm{K}^{+}$-ATPase activity increased by $35 \%-58 \%$ (Huetado et al.,2007; Pan et al.,2006). However, at present, the reports on low salt stress of crustaceans mainly focus on the gill of shrimp and crab, while the study on $\mathrm{Na}^{+}-\mathrm{K}^{+}$-ATPase activity of hepatopancreas of $P$. monodon had not been found yet. According to the results of this experiment, the low salinity stress of $10 \mathrm{ppt}$ and 20ppt had significant effect on the activity of $\mathrm{Na}^{+}-\mathrm{K}^{+}$-ATPase in hepatopancreas. Diet B and Diet A showed an increasing trend in 0-16h, then decreased and then increased. It was speculated that there may be two reasons: The first was that the increase of $\mathrm{Na}^{+}-\mathrm{K}^{+}$-ATPase provided energy for a large number of $\mathrm{Na}^{+}$and $\mathrm{K}^{+}$ions to be discharged. With the extension of salinity stress time, $\mathrm{Na}$ and $\mathrm{K}$ ions gradually balanced with the 
external environment, inhibiting $\mathrm{Na}^{+}-\mathrm{K}^{+}-$ATPase activity, and then the body gradually adapted to the environment, making $\mathrm{Na}^{+}-\mathrm{K}^{+}$-ATPase activity gradually return to the original level. Secondly, the increase of cortisol in hepatopancreas of $P$. monodon activated the activity of $\mathrm{Na}^{+}-\mathrm{K}^{+}$-ATPase in a short period of stress, which led to the increase of $\mathrm{Na}^{+}-\mathrm{K}^{+}$-ATPase activity.

\section{Acknowledgments}

This study was supported by National Key R \& D Program of China (2018YFD0901302), Central Public-interest Scientific Institution Basal Research Fund, CAFS (2020TD30), Financial Fund of Ministry of Agriculture and Rural affairs of China (NHYYSWZZZYKZX2020), Industrial Technology System of Modern Agriculture (CARS-48), Guangdong Provincial Special Fund For Modern Agriculture Industry Technology Innovation Teams (No. 2019KJ149).

\section{References}

Du J., Zhu H., Liu P., Chen J., Xiu Y.J., Yao W., Wu T., Ren Q., Meng Q.G., Gu W., Wang W., 2013. Immune responses and gene expression in hepatopancreas from Macrobrachium rosenbergii challenged by a novel pathogen spiroplasma MR-1008. Fish \& Shellfish Immunology, 34(1):315-323. https://doi.org/10.1016/j.fsi.2012.11.009

Fang W.H., 2001. The activity of $\mathrm{Na}^{+}-\mathrm{K}^{+}-$ATPase in the gill of Penaeus monodon. Journal of Shanghai Ocean University, 10(2):140-144.

Flik G., Klaren P.H., Burg M., Metz E.H., Huising M.O., 2006. CRF and stress in fish. General \& Comparative Endocrinology., 146(1), 36-44.

Ghyperlink H P., Mingarro M., Calduch-Giner J., Médale F., Pérez-Sánchez J., 2004. Protein growth performance, amino acid utilisation and somatotropic axis responsiveness to fish meal replacement by plant protein sources in gilthead sea bream (Sparus aurata). Aquaculture Amsterdam., 232:493-510

Guo Q.D., Xu G.C., Wang Y.J., Cheng R.B., Zhao H., Zhang W., Lv W.Q., 2013. Evaluation of the tolerance level of acute salinity stress to juvenile Pampus argenteus., Marine Environmental Science., 32(004):560-564.

Hurtado M.A., Racotta I.S., Civera R., Civera L., Ibarra M., Hernández-Rodríguez., E. Palacios., 2007. Effect of hypo- and hypersaline conditions on osmolality and $\mathrm{Na}+\mathrm{K}+-$ ATPase activity in juvenile shrimp (Litopenaeus vannamei) fed low- and high-HUFA diets. Comparative Biochemistry \& Physiology Part A Molecular \& Integrative Physiology, 147(3):703-710. https://doi.org/10.1016/j.cbpa.2006.07.002

Jiang S., Zhou F.L., Huang J.H., Yang Q.B., Yang L.S. and Jiang S.G., 2018. Effects of eyestalk ablation on feeding, gonad development and energy conversion of Penaeus monodon broodstock. Pakistan Jool., 50:1217-1223. http://dx.doi.org/10.17582/journal.pjz/2018.50.4.1217.1223

Liu X.H., Ye J.D., Wang K., Kong J.H., Yang W. and Zhou L., 2012. Partial replacement of fish meal with peanut meal in practical diets for the Pacific white shrimp, Litopenaeus vannamei. Aquaculture Research., 43(5):745-755. https://doi.org/10.1111/j.13652109.2011.02883.x

Lin S.M., Mao S.H., Guan Y., Pan Y., Luo L., Luo L., 2011. Study on the substitution of dephenolic cottonseed protein for fish meal in tilapia low fish meal feed. Journal of Animal Nutrition., 23(12):2231-2238.

Lin S.M ., Mai K.S., Tan B.P., Liu W.S., 2010. Effects of Four Vegetable Protein Supplementation on Growth, Digestive Enzyme Activities, and Liver Functions of Juvenile Tilapia, Oreochromis niloticus $\times$ Oreochromis aureus. Journal of the World Aquaculture Society, 41(4):583-593. https://doi.org/10.1111/j.1749-7345.2010.00398.x

McCormick S.D., 2001. Endocrine Control of Osmoregulation in Teleost Fish. American Zoologist., 41(4):781-794. 1569(2001)041[0781:ECOOIT]2.0.CO;2

Niu J., Chen X., Lu X., Jiang S.G., Lin H.Z., Liu Y.J., Huang Z., Wang J., Wang Y., Tian L.X., 2015. Effects of different levels of dietary wakame (Undaria pinnatifida) on growth, immunity and intestinal structure of juvenile Penaeus monodon. Aquaculture., 435:78-85. https://doi.org/10.1016/j.aquaculture.2014.08.013

Pan L.Q., Luan Z.H., Jin C.X., 2006. Effects of $\mathrm{Na}^{+} / \mathrm{K}^{+}$and $\mathrm{Mg}^{+} / \mathrm{Ca} 2^{+}$ratios in saline groundwaters on $\mathrm{Na}^{+}-\mathrm{K}^{+}$-ATPase activity, survival and growth of Marsupenaeus japonicus 
postlarvae.

Aquaculture,

261(4):1396-1402. https://doi.org/10.1016/j.aquaculture.2006.09.031

Pelis R.M , Mccormick S.D., 2001. Effects of Growth Hormone and Cortisol on $\mathrm{Na}^{+}-\mathrm{K}^{+} 2 \mathrm{Cl}$ Cotransporter Localization and Abundance in the Gills of Atlantic Salmon. General \& Comparative Endocrinology, 124(2):134-143. https://doi.org/10.1006/gcen.2001.7703

Qiao Y.B., Li S.S., Cui W.B., Zuo R.T., Chang Y.Q., 2020. Effects of acute salinity stress on the antioxidant and non-specific immunity of Procambarus clarkii. China Fishery Quality and Standards, 10(02):44-50.

Riche M. and Williams T.N., 2011. Fish meal replacement with solvent extracted soybean meal or soy protein isolate in a practical diet formulation for Florida pompano (Trachinotus carolinus,
L.) reared
in low salinity.
Aquaculture
Nutrition.,
17(4):368-379. https://doi.org/10.1111/j.1365-2095.2010.00808.x

Steven J., Brooks., 2006. Gill $\mathrm{Na}^{+}-\mathrm{K}^{+}$-ATPase in a series of hyper-regulating gammarid amphipods. Enzyme characterisation and the effects of salinity acclimation. Comparative Biochemistry \& Physiology Part A Molecular \& Integrative Physiology, 144:24-32. https://doi.org/10.1016/j.cbpa.2006.01.023

Sun I. M., Chen I. Q., Li E. C., 2013. Effects of methionine supplementation in high proportion cotton meal feed on feeding, growth and antioxidant enzyme activities of juvenile eriocheir sinensis., Journal of aquatic biology, 2:336-343.

Vinagre C., Madeira D., Luís Narciso., Henrique N., Cabral., Mário S., Diniz., 2012. Effect of handling, confinement and crowding in HSP70 production in Pachygrapsus marmoratus, a model species for climate change experiments. Journal of Sea Research, 72:62-68. https://doi.org/10.1016/j.seares.2012.05.013

Wendelaar Bonga S E., 1997. The stress response in fish. Physiological reviews., 77(3):591625.

Wunderink Y.S., Engels S., Halm S., Manuel Y Manu., Gonzalo., Marttzal-RodrzaloY., \& Flik G., 2011. Chronic and acute stress responses in senegalese sole (solea senegalensis): the involvement of cortisol, crh and crh-bp. Gen Comp Endocrinol., 171(2):203-210. https://doi.org/10.1016/j.ygcen.2011.01.010

Wu R., Xie S.T., Sun Y., WanYan X.Q., Zhang Q.Z., 2006. High Prokaryotic Expression of Heat Shock Protein 70 in Litopenaeus vannamei. Chinese Fisheries Science, 13(2):305-309.

Xiao K.Y., 2007. Aquatic animal immunity and application. Beijing: Science Press.

Xu T.H., Gao X.P., Liang Y.Q., Wang X.X., Zheng K.K., Chang Q., Wu L.X., 2012. Effects of replacing fish meal with low molecular hydrolyzed protein in high vegetable protein feed on growth performance and nonspecific immunity of Paralichthys olivaceus. Fishery Science Progress., 033(003):60-69.

Yu Y.Y., Chen W.D., Liu Y,J, Niu J., Chen M. and Tian L.X., 2016. Effect of different dietary levels of Gracilaria lemaneiformis dry power on growth performance, haematological parameters and intestinal structure of juvenile Pacific white shrimp (Litopenaeus vannamei). Aquaculture., 450:356-362. https://doi.org/10.1016/j.aquaculture.2015.07.037

Zhang C.X., Rahimnejad S., Wang Y.R., Lu K.L., Song K., Wang L. and Mai K.S., 2018. Substituting fish meal with soybean meal in diets for Japanese seabass (Lateolabrax japonicus): effects on growth, digestive enzymes activity, gut histology, and expression of gut inflammatory and transporter genes. Aquaculture., 483:173-182. https://doi.org/10.1016/j.aquaculture.2017.10.029

Zhang H.T., Pu X.S., Tan B.P., Dong X.H., Chi S.Y., Liu H.Y., Zhang S., 2018. Effects of high-protein cotton meal instead of fish meal on growth performance, non-specific immune indexes and disease resistance of Litopenaeus vannamei. Journal of Guangdong Ocean University., 038(004):20-26.

Zhou B., Kelly S.P., Ianowski J.P., Wood C.M., 2003. Effects of cortisol and prolactin on $\mathrm{Na}^{+}$ and $\mathrm{Cl}^{-}$transport in cultured branchial epithelia from $\mathrm{FW}$ rainbow trout. Am J Physiol Regul Integr Comp Physiol, 285(6): R1305-R1316. 